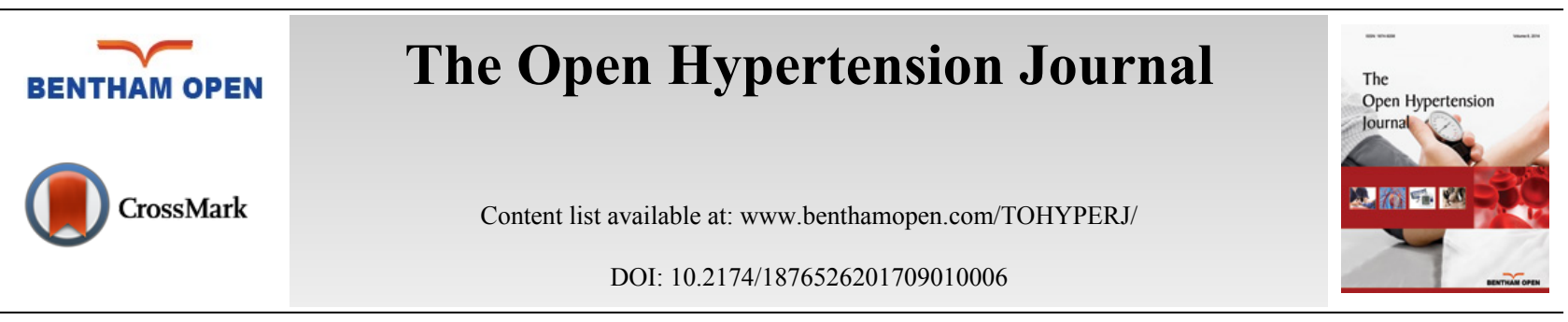

RESEARCH ARTICLE

\title{
Clinical Factors Affecting the Goal Blood Pressure in Hypertensive Patients of a Rural Polyclinic in Russia
}

\author{
Olga M. Posnenkova ${ }^{1}$, Stanislav N. Gerasimov ${ }^{2}$, Yulia V. Popova ${ }^{1}$, Ivan A. Popov ${ }^{1}$, Galina N. \\ Shemetova ${ }^{3}$, Vladimir I. Gridnev ${ }^{1}$ and Anton R. Kiselev ${ }^{1, *}$

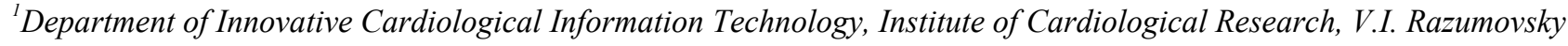 \\ State Medical University of Saratov, Saratov, Russia \\ ${ }^{2}$ V.I. Razumovsky State Medical University of Saratov, Saratov, Russia \\ ${ }^{3}$ Department of Polyclinic Therapy, V.I. Razumovsky State Medical University of Saratov, Saratov, Russia
}

Received: June 30, 2017

Revised: October 4, 2017

Accepted: November 25, 2017

\section{Abstract:}

\section{Background:}

Primary care units in rural areas of the Russian Federation experience difficulties in long-term follow-up of chronic cardiovascular diseases, such as hypertension. Identification of outpatient clinical traits affecting the goal blood pressure (BP) may optimize the choice of treatment pathways.

\section{Objective:}

To identify the patient-related factors affecting the achievement of the goal BP in the course of hypertension treatment at a rural polyclinic.

\section{Methods:}

We analyzed the data on 182 patients with essential hypertension ( $64.6 \pm 11.3$ yo; $48.5 \%$ men), who were treated in polyclinic settings of a rural settlement in the Saratov Region of the Russian Federation. Outpatient medical records were used as a source of clinical data. Repeat patients with hypertension diagnosis specified in their medical records, visiting a therapeutist or cardiologist on two randomly selected workdays, were enrolled in our study. The first appointment took place during 1-31 July, 2015 ( $n=88$ ), while the second visit occurred on 1- 31 July, $2016(n=94)$. Eleven district therapeutists, two general practitioners and the only cardiologist of the polyclinic participated in the study. Discriminant function analysis was used to identify factors affecting the achievement of the goal blood pressure in the patients. Basic demographic and anamnesis data, risk factors, medical treatment type and lifestyle modification measures, if any, which exhibited statistical significance in univariate analysis $(\mathrm{p}<0.05)$, were selected for multi-factor discriminant analysis.

\section{Results:}

The goal BP was achieved in 93 patients (51\%). The patients with the goal BP differed from those with uncontrolled hypertension in various ways. They were less often women $(53.8 \%$ vs. $69.7 \%, \mathrm{p}=0.028)$, more frequently had prior myocardial infarction $(22.6 \% \mathrm{vs}$. $10.1 \%, \mathrm{p}=0.024)$, more rarely suffered from other forms of stable CAD $(55.9 \%$ vs. $73 \%, \mathrm{p}=0.016)$, as well as took fewer thiazidelike diuretics $(9.7 \%$ vs $21.3 \%, \mathrm{p}=0.03)$. It is worth noting that fewer antihypertensive medications were prescribed to the patients with the goal BP as opposed to those with poor BP control ( $1.63 \pm 0.12$ vs. $1.98 \pm 0.11, \mathrm{p}=0.018)$.

Resulting discriminant model exhibited high predictive power. The ratio of odds for the model was $5.4(95 \% \mathrm{CI}: 2.7-10.7), \mathrm{p}<0.001$. The single factor correlating significantly with the achievement of the goal BP was preceding myocardial infarction (OR $2.6,95 \%$ CI: $1.1-6.6, p=0.032$ ), while prescription of two or more antihypertension drugs was associated with poor BP control (OR $0.4,95 \%$

* Address correspondence to this author at the Institute of Cardiological Research, V.I. Razumovsky State Medical University of Saratov, 112, Bolshaya Kazachya Str, Saratov 410012, Russia, Tel: +7 8452 393978; Fax: +7 84523939 96; Email: kiselev@cardio-it.ru 
CI: $0.2-0.7, p=0.003)$.

\section{Conclusion:}

In the hypertensive patients with a history of myocardial infarction versus those without it, treated at a rural polyclinic, BP was more likely to be controlled. Administration of multiple antihypertensive drugs was associated with poor BP control.

Keywords: Hypertension, Goal blood pressure, Clinical factors, Blood pressure control, Rural polyclinic, Follow-up.

\section{INTRODUCTION}

Hypertension is a frequent medical condition among the patients of primary care units worldwide, including the Russian Federation. However, the cause of a visit is usually not hypertension per se, because this disorder is predominantly asymptomatic. Patients with hypertension measure their blood pressure (BP) at home systematically, and even in rural areas of Russia, they take antihypertensive drugs quite regularly [1]. Despite that, BP remains uncontrolled even in those who visit a physician [2]. Nevertheless, a proper long-term BP control is the essential goal of the hypertension treatment [3]. It is crucial to prevent the target organ damage, since it may cause various fatal and nonfatal complications of elevated BP, such as stroke, myocardial infarction, sudden death, heart failure, peripheral artery disease, and end-stage renal disease.

In rural and remote areas of Russia, where availability of specialized and well-equipped healthcare services is low, the prevention of cardiovascular disorders is extremely important.

Recently, much attention was paid to the prevention of cardiovascular conditions at the national level [4]. Periodic preventive screening of adults is conducted at all Russian polyclinics. It is aimed at detection of cardiovascular risk factors, including hypertension. Hence, increasingly more cases of hypertension are diagnosed, while every case should be treated effectively, with an outcome of the goal BP equal or less than 140/90 mm Hg [5].

A little is known about the predictors of a proper BP control in the patients treated at Russian polyclinics, especially in those living in rural areas. It is generally assumed that village residents have worse health condition due to low availability of healthcare services, and that they are in demand of somewhat stricter follow-up and monitoring procedures.

Identification of the patient traits affecting the establishment of the goal BP would facilitate the choice of the most effective treatment interventions, as well as the selection of hypertensives from remote areas with supposedly uncontrolled BP for health screening purposes.

The goal of our study was to determine patient-related factors affecting the establishment of the goal BP in hypertensive patients treated at a rural polyclinic.

\section{MATERIAL AND METHODS}

\subsection{Enrollment}

Study participants were enrolled from the pool of hypertensive patients visiting a therapeutist or cardiologist at the Engels city polyclinic No. 4 (Saratov Region, Russia) on any workday in July, 2015, and July, 2016. Exact patient visitation date was selected randomly for every participating physician: eleven district therapeutists, two general practitioners and the only cardiologist of the polyclinic who participated in the study. Doctors informed their patients about the study and obtained written consents from those who agreed to participate in it.

\subsection{Study Setting and Patient Selection Procedure}

The study was conducted at the Engels city polyclinic No. 4, Engels, Russia, the only polyclinic available to the residents of Privolzhskiy rural settlement, located in the Engels District of the Saratov Region, Russian Federation. The population of Privolzhskiy is near 34,000 inhabitants. The number of adults who attended the Engels city polyclinic No. 4 amounted to 26,741 in 2016.

We selected 182 patients ( $64.6 \pm 11.3$ yo; $48.5 \%$ men) with essential hypertension in our research. They represented $0.7 \%$ of the total adult population of the village and $6 \%$ of 3080 patients diagnosed with hypertension at the polyclinic.

The following inclusion criteria were employed: 
i. Age $\geq 18$ yo;

ii. Diagnosis of hypertension in medical records.

Patients were excluded from the study if they had at least one of the following exclusion criteria:

i. Secondary hypertension;

ii. Reluctance to participate.

Upon enrollment into the study, all patients were split in two groups based on recorded BP values at their last visit to a physician: controlled group (those with established goal BP, n=93) and uncontrolled group (those who did not achieve the goal BP, $n=89$ ). The goal BP was considered to be achieved if its value at the last visit was less than 140/90 $\mathrm{mm} \mathrm{Hg}$. If the last visit BP was recorded at higher values, a patient was classified into the uncontrolled group.

Auscultatory sphygmomanometers were used to measure BP. The exact times of BP measurement varied among the patients from 8 am to $4 \mathrm{pm}$, which matched the routine outpatient visits during regular requested to collect the data from the patient medical records regarding conventional demographics, family status, anamnesis, as well as physical examination (height, weight, and waist circumference), laboratory and instrumental findings throughout previous 12 months. Antihypertensive treatment administered at the last visit was also assessed.

\subsection{Study Design}

First, we compared patients with controlled and uncontrolled BP. As a result, we identified significant differences between the groups.

Next, we selected clinical parameters for multiple analyses (in particular, discriminant function analysis). We used the following criteria for parameter selection:

i. Statistically significant differences between studied patient groups on particular parameter;

ii. Presence of a quantified parameter in two-thirds of the medical records;

iii. Independence of other considered parameters.

Finally, we performed a discriminant function analysis to identify the set of the patient clinical traits yielding the best discrimination between the patients with optimal BP control and those with uncontrolled BP.

\subsection{Statistical Analysis}

We used the Shapiro-Wilk test to identify whether the data were approximately normally distributed. Since some data did not comply with normal distribution, their further analysis was conducted using non-parametric statistical methods. We employed the Chi-square $(\chi 2)$ test to compare the binary variables and to compute the significance level for the difference between two proportions. Mann-Whitney test was used for comparison of continuous variables. Categorical data were presented as frequencies and percentages with 95\% confidence intervals - M (95\% CI). Continuous variables were reported as medians and inter-quartile ranges (lower and upper quartiles) - Me (LQ, UQ).

Backward stepwise procedure of the discriminant function analysis was selected to determine the set of patient clinical traits yielding the best discrimination between the $\mathrm{BP}<140 / 90 \mathrm{~mm} \mathrm{Hg}$ and $\mathrm{BP} \geq 140 / 90 \mathrm{~mm} \mathrm{Hg}$ at the last outpatient visit. We employed the following stepwise options to eliminate factors under the analysis: the tolerance value of 0.01 , move value of $\mathrm{F}$ was 10.0 , and the number of steps was unlimited.

The obtained estimations were considered statistically significant at $p<0.05$. For the statistical analysis, the software package Statistica 6.1 (Statsoft Inc., USA) was used.

\section{RESULTS}

\subsection{Characteristics of the Patients with Controlled and Uncontrolled BP}

Of the total sample recruited to the study, 93 patients (51\%) achieved the goal BP. Clinical characteristics of the patients according to BP control are presented in Table (1). Systolic BP (SBP) and diastolic BP (DBP) levels [data presented as Me (LQ, UQ)] in the controlled group were $120(115,130) \mathrm{mm} \mathrm{Hg}$ and $70(65,80) \mathrm{mm} \mathrm{Hg}$, respectively. In the uncontrolled group, SBP was $145(140,152) \mathrm{mm} \mathrm{Hg}$, while DBP was $85(80,90) \mathrm{mm} \mathrm{Hg}$ (p $<0.001$ for both 
SBP and DBP).

Table 1. Demographics and clinical traits of the patients with hypertension treated in rural polyclinic settings versus BP control.

\begin{tabular}{|c|c|c|c|}
\hline Variables & Controlled group (n=93) (51\%) & Uncontrolled group $(n=89)(49 \%)$ & p-values \\
\hline Female (\%), M (95\% CI) & $53.8(43.4-64.1)$ & $69.7(59.9-79.4)$ & 0.028 \\
\hline Age (yrs), Me (LQ, UQ) & $66(57,74)$ & $68(62,75)$ & 0.059 \\
\hline BMI $\left(\mathrm{kg} / \mathrm{m}^{2}\right), \mathrm{Me}(\mathrm{LQ}, \mathrm{UQ})$ & $29.2(25.8,32.2)$ & $29.4(28.7,37.7)$ & 0.921 \\
\hline Angina pectories (\%), M (95\% CI) & $16.1(8.5-23.7)$ & $11.2(4.5-17.9)$ & 0.339 \\
\hline Prior myocardial infarction (\%), M (95\% CI) & $22.6(13.9-31.2)$ & $10.1(3.7-16.5)$ & 0.024 \\
\hline CAD, other (\%), M (95\% CI) & $55.9(45.6-66.2)$ & $73.0(63.6-82.4)$ & 0.016 \\
\hline Peripheral arteries disease (\%), M (95\% CI) & $7.5(2.1-12.9)$ & $7.9(2.2-13.6)$ & 0.932 \\
\hline SBP (mm Hg), Me (LQ, UQ) & $120(115,130)$ & $145(140,152)$ & $<0.001$ \\
\hline DBP (mm Hg), Me (LQ, UQ) & $70(65,80)$ & $85(80,90)$ & $<0.001$ \\
\hline Total cholesterol (mg/dl), Me (LQ, UQ) & $186(171,217)$ & $213(190,229)$ & 0.012 \\
\hline Triglycerides (mg/dl), Me(LQ, UQ) & $72(61,88)$ & $96(65,175)$ & 0.271 \\
\hline Creatinine (mg/dl), Me (LQ, UQ) & $1.1(0.9,1.2)$ & $1.0(0.9,1.1)$ & 0.177 \\
\hline Left ventricle hypertrophy on ECG (\%), M (95\% CI) & $7.5(2.1,12.9)$ & $22.5(13.6,31.3)$ & 0.004 \\
\hline Smoking cessation advice (\%), M (95\% CI) & $2.2(0.9-5.2)$ & $1.1(0.1-3.4)$ & 0.588 \\
\hline Dietary counseling $(\%), \mathrm{M}(95 \% \mathrm{CI})$ & $53.8(43.4-64.1)$ & $55.1(44.5-65.6)$ & 0.861 \\
\hline Advice on physical activity (\%), M (95\% CI) & $5.4(0.7-10.1)$ & $7.9(2.2-13.6)$ & 0.500 \\
\hline Antihypertensive treatment $(\mathrm{n}), \mathrm{M} \pm \mathrm{SD}$ & $1.63 \pm 0.12$ & $1.98 \pm 0.11$ & 0.018 \\
\hline No antihypertensive drugs (\%), M (95\% CI) & $12.9(6.0-19.8)$ & $9.0(2.9-15.0)$ & 0.406 \\
\hline One antihypertensive drug (\%), M (95\% CI) & $40.9(30.7-51.0)$ & $21.3(12.7-30.0)$ & 0.005 \\
\hline Two antihypertensive drugs (\%), M (95\% CI) & $21.5(13.0-30.0)$ & $39.3(29.0-49.7)$ & 0.010 \\
\hline Three or more antihypertensive drugs (\%), M (95\% CI) & $24.7(15.8-33.7)$ & $30.3(20.6-40.1)$ & 0.399 \\
\hline ACE-inhibitors (\%), M (95\% CI) & $27.9(18.7-37.2)$ & $39.3(29.0-49.7)$ & 0.105 \\
\hline ARBs (\%), M (95\% CI) & $29.0(19.6-38.4)$ & $30.3(20.6-40.1)$ & 0.848 \\
\hline Beta-blockers (\%), M (95\% CI) & $46.2(35.9-56.6)$ & $57.3(46.8-67.8)$ & 0.136 \\
\hline Dihydrapiridine calcium antagonists (\%), M (95\% CI) & $20.4(12.1-28.8)$ & $21.3(12.7-30.1)$ & 0.879 \\
\hline Non-dihydrapiridine calcium antagonists (\%), M (95\% CI) & $4.3(0.1-8.5)$ & $3.4(0.1-7.2)$ & 0.745 \\
\hline Loop diuretics (\%), M (95\% CI) & $8.6(2.8-14.4)$ & $9.0(2.9-15.0)$ & 0.927 \\
\hline Thiazide diuretics $(\%), \mathrm{M}(95 \% \mathrm{CI})$ & $3.2(0.1-6.9)$ & $6.7(1.4-12.1)$ & 0.275 \\
\hline Thiazide-like diuretics (\%), M (95\% CI) & $9.7(3.6-15.8)$ & $21.4(12.7-30.0)$ & 0.030 \\
\hline Potassium-sparing diuretics (\%), M $(95 \% \mathrm{CI})$ & $14.0(6.8-21.2)$ & $9.0(2.9-15.0)$ & 0.294 \\
\hline
\end{tabular}

ACE, angiotensin-converting enzyme; ARB, angiotensin receptor blocker; CAD, coronary arteries disease; CI, confidence interval; ECG, electrocardiogram; LDL, low density lipoprotein; DBP, diastolic blood pressure; SBP, systolic blood pressure; SD, standard deviation.

There were no significant age-related differences found between the groups, but sex distribution differed significantly. Age [Me (LQ, UQ)] was 66 yo $(57,74)$ in the patients with controlled BP and 68 yo $(62,75)$ in the patients with uncontrolled BP $(\mathrm{p}=0.059)$. There were more women among the patients with uncontrolled BP compared with the group, in which the goal BP level was achieved: 69.7 (59.9 - 79.4) vs. 53.8 (43.4 - 64.1), M (95\% CI), respectively.

Patients with the goal BP differed from the patients with uncontrolled hypertension on the following traits of their clinical status. They had more frequent prior myocardial infarction: $22.6 \%(13.9-31.2) \mathrm{vs.} 10.1 \%(3.7-16.5), \mathrm{M}(95 \%$ $\mathrm{CI}), \mathrm{p}=0.024$. However, they suffered less often from stable CAD other than angina: $55.9 \%(45.6-66.2) \mathrm{vs} .73 .0 \%$ $(63.6-82.4), \mathrm{p}=0.016$. The frequencies of stable angina occurrence were virtually similar in the both groups: $16.1 \%$ $(8.5-23.7)$ vs. $11.2 \%(4.5-17.9), p=0.339$. The patients in the controlled group had lower total cholesterol level, compared with uncontrolled patients: $186(171,217) \mathrm{mg} / \mathrm{dl}$ vs. $213(190,229) \mathrm{mg} / \mathrm{dl}, \mathrm{Me}(\mathrm{LQ}, \mathrm{UQ}), \mathrm{p}=0.012$. Merely $7.5 \%(2.1 ; 12.9)$ of the patients [M $(95 \% \mathrm{CI})]$ with the goal BP showed ventricle hypertrophy on electrocardiogram, whereas in the poor BP control group, left ventricle hypertrophy was quite pronounced in $22.5 \%(13.6,31.3)$ of the patients. Patients with controlled BP were taking significantly fewer thiazide-like diuretics (9.7\% vs. 21.3\%, $\mathrm{p}=0.030)$. Other major classes of antihypertensive drugs were administered similarly to the controlled and uncontrolled groups. The number of antihypertensive drugs prescribed to the patients with the goal BP were $1.63 \pm 0.12 \mathrm{vs.} 1.98 \pm 0.11$ in the patients with poor BP control $(\mathrm{p}=0.018)$. Single antihypertensive drug was administered to $40.9 \%(30.7-51.0)$ of the 
patients in the controlled group and to $21.3 \%(12.7-30.0)$ of the patients in the uncontrolled group, $p=0.005$. Two antihypertensive drugs were taken by $21.5 \%$ (13.0 - 30.0) of hypertensives with the goal BP vs. $39.3 \%(29.0-49.7)$ of the patients with poor BP control. The proportions of the patients, who were administered multiple medicines or received no antihypertensive drugs, were similar in both groups. Documented advices on lifestyle modification were rarely observed in patient medical records independently from BP control.

\subsection{Association Between Patient Clinical Traits and Establishment of the Goal BP}

All parameters of the patient clinical status, which showed significant differences between the studied groups, were further subject to discriminant function analysis, aimed to assess their applicability to classifying the patients based on BP control. The following factors were selected by developed statistical model Table (2): coronary artery disease other then myocardial infarction and stable angina, male sex, thiazide-like diuretics, number of antihypertensive drugs, total cholesterol, prior myocardial infarction. We did not include left ventricular hypertrophy on ECG in the analysis because of incompleteness of medical records data. Summaries of discriminant function analysis and canonical analysis are presented in Tables (3 and 4). Constructed discriminant model exhibited high predictive power in goal BP achievement: the ratio of odds for the model was 5.4 (95\% CI: 2.7-10.7), $\mathrm{p}<0.001$.

Table 2. Association between the goal BP establishment and clinical parameters of hypertensive patients in rural polyclinic settings: The results of discriminant function analysis.

\begin{tabular}{|c|c|c|}
\hline Variables & Pooled-within-groups correlations & p-values \\
\hline Other CAD & -0.53 & 0.560 \\
\hline Male sex & -0.48 & 0.302 \\
\hline Thiazide-like diuretics & -0.48 & 0.430 \\
\hline Number of antihypertensive drugs & -0.47 & 0.046 \\
\hline Total cholesterol & 0.49 & 0.142 \\
\hline Prior myocardial infarction & 0.50 & 0.036 \\
\hline
\end{tabular}

$\mathrm{BP}$, blood pressure; CAD, coronary arteries disease.

Table 3. Discriminant function analysis summary.

\begin{tabular}{|c|c|c|c|c|}
\hline Variables & Wilks' lambda & $\boldsymbol{F}$-remove (1.175) & $\boldsymbol{p}$-values & Tolerance \\
\hline Prior myocardial infarction & 0.917 & 4.476 & 0.036 & 0.74 \\
\hline Number of antihypertensive medications & 0.915 & 4.039 & 0.046 & 0.85 \\
\hline Total cholesterol & 0.906 & 2.171 & 0.142 & 0.78 \\
\hline Male sex & 0.900 & 1.073 & 0.302 & 0.92 \\
\hline Thiazide-like diuretics & 0.898 & 0.623 & 0.430 & 0.89 \\
\hline Other CAD & 0.896 & 0.340 & 0.560 & 0.72 \\
\hline
\end{tabular}

No. of variables in the model: 6. Grouping: goal BP achievement (two groups). Wilks' lambda: 0.895. $p=0.003$.

Table 4. Canonical analysis summary.

\begin{tabular}{|c|c|c|}
\hline Variables & Raw coefficients & Standardized coefficients \\
\hline Prior myocardial infarction & 1.145 & 0.449 \\
\hline Number of antihypertensive drugs & -0.160 & -0.179 \\
\hline Total cholesterol & 0.001 & 0.509 \\
\hline Male sex & 0.812 & 0.401 \\
\hline Thiazide-like diuretics & -0.601 & -0.180 \\
\hline Other CAD & -1.224 & -0.576 \\
\hline Constant & -2.929 & - \\
\hline Eigenvalue & 0.258 & 0.258 \\
\hline Cumulative proportion & 1.000 & 1.000 \\
\hline
\end{tabular}

The raw coefficients of canonical function can be used to compute raw canonical scores for each case in each discriminant model. The eigenvalues for each discriminant function and the cumulative proportion of variance extracted by each discriminant function are also presented above. The standardized coefficients were computed by multiplying raw coefficients by the square root of the pooled within-group co-variances for respective variables. 
Clinical parameter, predicting a proper BP control, was preceding myocardial infarction: odds ratio 2.6 (95\% CI: 1.1 $-6.6), p=0.036$. Increasing the number of antihypertensive drugs was significantly associated with the lack of BP control: odds ratio $0.4(95 \% \mathrm{CI}: 0.2-0.7), \mathrm{p}=0.046$.

\section{DISCUSSION}

The data on BP control quality among hypertensive patients in Russia is usually derived from epidemiological studies [6, 7], and little is known about the goal BP establishment in primary care settings, specifically in rural polyclinics. Notably, the goal BP achievement in the patients with hypertension diagnosis is assessed quarterly at all Russian polyclinics, but these data are not available to the general public. Our survey is the first local cross-sectional observational study for the Volga Federal District of European Russia that provided the data on BP control quality in hypertensive patients treated at a rural polyclinic. These data can be compared with the results of the national hypertension registry [8], other national and international data on effectiveness of BP control in primary care settings. According to the 2014 Russian Registry of Hypertension, Coronary Artery Disease \& Chronic Heart Failure, 44\% of hypertensives treated in primary care settings had BP $<140 / 90 \mathrm{~mm} \mathrm{Hg}$ at their last visit to a physician [9]. Our findings have demonstrated that $51 \%$ of the patients with hypertension treated at the polyclinic of a rural settlement in 2015/2016 had achieved the goal BP. Previous Russian hypertension registry has shown that goal BP levels were maintained in $28 \%$ of the outpatients with diagnosed hypertension. However, the criteria for the goal BP maintenance were stricter than for the goal BP establishment [10]. In Yaroslavl Region of the Russian Federation, BP control rate $(<$ $140 / 90 \mathrm{~mm} \mathrm{Hg}$ ) among hypertensive patients visiting government-run outpatient health facilities was $23 \%$ in 2012 [11] and $33 \%$ in 2014 [12]. The level of BP control in present study was lower, compared with the data of the national hypertension registry due to the differences in inclusion criteria. For example, in Yaroslavl, only those patients, whose visits were related to hypertension, were included into statistical report. In contrast, the registry included all patients with diagnosed hypertension who visited outpatient settings independently of the cause of their visit to a physician [8]. The data from Ivanovo Region participating in the national registry demonstrated $46 \%$ of controlled BP in the patients with hypertension in 2015 [13]. Thus, the degree of BP control in case of the polyclinic in our study is still higher than nationwide results suggest.

We have also found numerous studies on BP control conducted in primary care settings in different countries showing the following results. The rate of hypertension control (latest BP level, $<140 / 90 \mathrm{~mm} \mathrm{Hg}$ ) was $63 \%$ in the United States of America and 31-46\% in five European countries (France, Germany, Italy, Spain and United Kingdom) [14]. Notably, the earlier American study conducted at 20 primary care practices in 14 states showed that BP was controlled in $49.8 \%$ of all hypertensive patients with wide variability among the practices (25.5-66.6\%) [15]. Hypertension was controlled in $44 \%$ of Jordanian patients attending outpatient cardiology clinics [16]. In Sweden, BP < 140/90 mm Hg was reported in $27 \%$ of 21167 hypertensives over 30 years old who have visited primary health-care centers [17]. In Switzerland, 53.8\% of treated hypertensive patients who visited physicians across the country achieved the BP goals [18]. Swiss cross-sectional study suggested that $56.9 \%$ of the patients had BP measurements $<140 / 90 \mathrm{~mm}$ $\mathrm{Hg}$ [19]. In the TURKSAHA study, the rate of successful BP control ( $<140 / 90 \mathrm{~mm} \mathrm{Hg}$; for diabetics $<130 / 80 \mathrm{~mm} \mathrm{Hg}$ ) was $26.2 \%$ [20]. Presented data demonstrate a wide range of between- and within-country variations in BP control. The data from Russia are comparable with the results of European countries and the U.S, and are only slightly lower than the results of the most developed EU countries, such as Switzerland. Our findings supported the data presented in current national hypertension registry.

Compared with the data on BP control, patient-related traits affecting the goal BP in primary care services are studied much worse, especially in Russia. Previous research surveys of these issues revealed various patient traits responsible for proper or poor BP control. Cerebrovascular diseases, coronary arteries disease, body mass index less than $28 \mathrm{~kg} / \mathrm{m}^{2}$, LDL-cholesterol level (lower LDL-cholesterol levels match higher probability of BP control) predicted the goal BP establishment in Italian hypertensive diabetics [21]. BP control among the U.S. hypertensives was associated with age of 60 years old or younger, female sex, multiple visits to a physician, and multiple comorbidities [15].

In Jordanian hypertensives, of all studied clinical traits and administered medications, which were subjected to multivariate logistic regression analysis, only the presence of diabetes mellitus was found to be inversely associated with BP control [16]. In contrast, control rates in Canadian study did not differ among overall hypertensive population and those with comorbidity [22].

Among the U.S. hypertensives that were aware of their condition, such variables, as age of at least 65 years old, 
male sex, and not having visited a physician within the preceding twelve-month period, were independently associated with poor BP control [23]. Similarly, M.P. Ho et al. revealed that treatment intensification during previous six months was a predictor of uncontrolled BP in hypertensive patients [24]. Another U.S. study [25] has shown that Caucasians and patients taking lipid-lowering therapy were most likely to reach the goal BP by means of combination therapy. Severe hypertension, an established need for more antihypertensive drugs and target organ damage were strong predictors of uncontrolled hypertension.

In Russia, the following factors affecting the BP control were previously indicated: obesity, dyslipidemia [26], poor adherence to treatment [27 - 29], and several combinations of comorbidities [30].

In the present study, we revealed that prior myocardial infarction was associated with the goal BP establishment, whereas treatment with multiple antihypertensive agents lowered the probability of a proper BP control. As for myocardial infarction, we propose that patients surviving after this life-threatening condition become more susceptible to the treatment. Moreover, they should take multiple obligatory antihypertensive medications for prevention of further cardiovascular disorders. Furthermore, BP could decline due to impaired pumping function of their heart caused by myocardium injury.

Another result, related to better BP control in hypertensive patients taking fewer medications appears paradoxical. Still, it completely agrees with the data by S.A. Shalnova et al. [31] and N. Hatori et al. [32]. One of possible explanations of this fact is higher adherence to monotherapy, while another suggests that less aggressive treatment is commonly used in low- and intermediate risk patients or in patients with newly diagnosed hypertension. In the latter case, it is quite simple to control hypertension. Therefore, our results did not conflict with the previous data on the subject and supported some of these.

\section{CONCLUSION}

The present study added new data on BP control in hypertensive patients treated in rural areas, as well as elucidated some aspects of hypertension management in Russian primary care settings.

Our findings suggested that, in patients treated at a rural polyclinic, essential hypertension complicated by myocardial infarction is more likely to be controlled. Administering multiple antihypertensive medications was associated with poor BP control.

\section{LIMITATIONS}

Several factors, which were not considered in the present study, may also influence the validity of results on predictors of the goal BP establishment. In our analysis, we included only the factors differing significantly between the groups of the patients with controlled and uncontrolled BP. The influence of some conventional parameters usually associated with poor BP control, such as age, sex, BMI, socioeconomic stress, very high BP and dyslipidemia were not investigated in our study due to the absence of between-group differences.

We used only medical records to analyze BP values in relation to the patient clinical traits and treatment options. Some cases represented newly diagnosed hypertension, and we could not conclude to what extent the goal BP represented an actual BP obtained in the course of some particular treatment, including the cases of nonpharmacological treatment as initial treatment strategy for low- and intermediate risk patients. Also, medications may have been prescribed, while the patient did not purchase the prescription.

We did neither investigate whether appropriate dosages of the medications were used, nor assess the patients' adherence to antihypertensive therapy that may influence the degree of BP control [27, 28].

The causes of visits to the polyclinic were not analyzed as well. If the cause of a visit was not cardiovascular, a physician may have not recorded antihypertensive medications a patient was treated with. If the cause of a visit was not hypertension, even if it was cardiovascular, a patient was more likely to be controlled than uncontrolled.

Evaluating the factors attributing to healthcare service availability and organization of healthcare care process at the studied rural polyclinic, along with patient-doctor communication patterns were beyond the scope of our study, while such factors seem to be very important. Several studies demonstrated the impact of those on the quality of BP control [33].

We did not evaluate the impact of weather on BP. The study was conducted in summer. In this season, health condition is fairly stable in the majority of hypertensive patients, and BP is the lowest, which is supported by the data 
on seasonality of BP levels [34, 35].

Relatively small sample size in our study affected the generalizability of our findings. This should be taken into account when our study results are compared with those of other research projects.

\section{ETHICS APPROVAL AND CONSENT TO PARTICIPATE}

The study was approved by the Ethics Committee of V.I. Razumovsky State Medical University of Saratov (Saratov, Russia).

\section{HUMAN AND ANIMAL RIGHTS}

No animals were used in this research. All research procedures followed were in accordance with the ethical standards of the committee responsible for human experimentation (institutional and national), and with the Helsinki Declaration of 1975, as revised in 2008 (http://www.wma.net/en/20activities/10ethics/10helsinki/)

\section{CONSENT FOR PUBLICATION}

Not applicable.

\section{CONFLICT OF INTEREST}

The authors confirm that the article content has no conflict of interest. The authors have not received any financial support for the preparation of this manuscript.

\section{ACKNOWLEDGEMENTS}

We thank Irina Alexandrova for organizing recruitment procedure and all participating physicians for data collection.

\section{REFERENCES}

[1] Gerasimov SN, Korotin AS, Alexandrova IN, Popova YuV. Evaluation of treatment of patients with essential hypertension at primary care units using structured questionnaires (a polyclinic of the Saratov region as an example). Saratov Journal of Medical Scientific Research 2016; 12: $560-5$.

[2] Gerasimov SN, Alexandrova IN. Potential of a registry in evaluation of treatment of patients with essential hypertension in primary care (using the example of polyclinic located in Saratov region). Cardio-IT 2015; 2: e0403.

[http://dx.doi.org/10.15275/cardioit.2015.0403]

[3] Mancia G, Fagard R, Narkiewicz K, et al. 2013 ESH/ESC Guidelines for the management of arterial hypertension: The Task Force for the management of arterial hypertension of the European Society of Hypertension (ESH) and of the European Society of Cardiology (ESC). J Hypertens 2013; 31(7): 1281-357.

[http://dx.doi.org/10.1097/01.hjh.0000431740.32696.cc] [PMID: 23817082]

[4] Pogosova NV, Yufereva YM, Samorodskaya IV, Boytsov SA. Preventional screening: All pros and contras. Cardiovasc Ther Prev (Fidenza) 2016; 15(3): 4-13.

[http://dx.doi.org/10.15829/1728-8800-2016-3-4-13]

[5] Drozda J Jr, Messer JV, Spertus J, et al. ACCF/AHA/AMA-PCPI 2011 performance measures for adults with coronary artery disease and hypertension: A report of the American College of Cardiology Foundation/American Heart Association Task Force on Performance Measures and the American Medical Association-Physician Consortium for Performance Improvement. Circulation 2011; 124(2): 248-70. [http://dx.doi.org/10.1161/CIR.0b013e31821d9ef2] [PMID: 21670226]

[6] Oganov RG, Timofeeva TN, Koltunov IE, Konstantinov VV, Balanova YA, Kapustina AV, et al. Arterial hypertension epidemiology in Russia: The results of 2003-2010 federal monitoring. Cardiovasc Ther Prev (Fidenza) 2011; 10: 9-13.

[7] Boytsov SA, Balanova YuA, Shalnova SA, Deev AD, Artamonova GV, Gatagonova TM, et al. Arterial hypertension among individuals of 25-64 years old: Prevalence, awareness, treatment and control. By the data from ECCD. Cardiovasc Ther Prev (Fidenza) 2014; 13 (4): 4-14. [http://dx.doi.org/10.15829/1728-8800-2014-4-4-14]

[8] Gridnev VI, Kiselev AR, Posnenkova OM, Popova YuV, Lazareva NV, Belova OA, et al. Objectives and design of Russian Registry of Hypertension, Coronary Artery Disease, and Chronic Heart Failure. Russ Open Med J 2017; 6: e0201. [http://dx.doi.org/10.15275/rusomj.2017.0201]

[9] Posnenkova OM, Korotin AS, Kiselev AR, Gridnev VI, Belova OA, Rachkova SA, et al. Performance of recommended measures on risk factors control in patients with hypertension, coronary artery disease and chronic heart failure: the data from 2014 Russian registry. Cardio-IT 2015; 2: e0102.

[http://dx.doi.org/10.15275/cardioit.2015.0102] 
[10] Posnenkova OM, Kiselev AR, Gridnev VI, Schwartz VA, Dovgalevskyi PYa, Oshchepkova EV. Blood pressure control in primary care patients with arterial hypertension: Analysing the Hypertension Register data. Cardiovasc Ther Prev (Fidenza) 2012; 11(3): 4-11.

[11] Mozheyko M, Eregin S, Vigdorchik A, et al. Changes in hypertension treatment in the yaroslavl region of Russia: improvements observed between 2 cross-sectional surveys. J Clin Hypertens (Greenwich) 2013; 15(12): 918-24. [http://dx.doi.org/10.1111/jch.12214] [PMID: 24118731]

[12] Mozheyko M, Eregin S, Danilenko N, et al. Hypertension in Russia: changes observed after 4 years of a comprehensive health system improvement program in the Yaroslavl region. J Clin Hypertens (Greenwich) 2017; 19(2): 198-204. [http://dx.doi.org/10.1111/jch.12885] [PMID: 27534595]

[13] Belova OA, Rachkova SA, Shutemova EA, Romanchuk SV. Risk factors control in patients with cardiovascular diseases in Ivanovo region: Possibilities of a regional registry. Cardio-IT 2016; 3: e0102. [http://dx.doi.org/10.15275/cardioit.2016.0102]

[14] Wang YR, Alexander GC, Stafford RS. Outpatient hypertension treatment, treatment intensification, and control in Western Europe and the United States. Arch Intern Med 2007; 167(2): 141-7. [http://dx.doi.org/10.1001/archinte.167.2.141] [PMID: 17242314]

[15] Ornstein SM, Nietert PJ, Dickerson LM. Hypertension management and control in primary care: A study of 20 practices in 14 states. Pharmacotherapy 2004; 24(4): 500-7. [http://dx.doi.org/10.1592/phco.24.5.500.33359] [PMID: 15098805]

[16] Bulatova NR, Yousef A-M, AbuRuz SD, Farha RA. Hypertension management and factors associated with blood pressure control in Jordanian patients attending cardiology clinic. Trop J Pharm Res 2013; 12: 827-33.

[17] Qvarnström M, Wettermark B, Ljungman C, et al. Antihypertensive treatment and control in a large primary care population of 21 167 patients. J Hum Hypertens 2011; 25(8): 484-91. [http://dx.doi.org/10.1038/jhh.2010.86] [PMID: 20720572]

[18] Schäfer HH, Sudano I, Theus GR, Noll G, Burnier M. Target blood pressure attainment with antihypertensive therapy in Swiss primary care. Blood Press 2012; 21(4): 211-9.

[http://dx.doi.org/10.3109/08037051.2012.656395] [PMID: 22339442]

[19] Brenner R, Waeber B, Allemann Y. Medical treatment of hypertension in Switzerland. The 2009 Swiss Hypertension Survey (SWISSHYPE). Swiss Med Wkly 2011; 141: w13169. [PMID: 21374529]

[20] Abaci A, Kozan O, Oguz A, et al. Prescribing pattern of antihypertensive drugs in primary care units in Turkey: Results from the TURKSAHA study. Eur J Clin Pharmacol 2007; 63(4): 397-402. [http://dx.doi.org/10.1007/s00228-007-0266-8] [PMID: 17279356]

[21] de Pablos-Velasco P, Gonzalez-Albarran O, Estopiñan V, Khanbhai A. Blood pressure, antihypertensive treatment and factors associated with good blood pressure control in hypertensive diabetics: The Tarmidas study. J Hum Hypertens 2007; 21(8): 664-72. [http://dx.doi.org/10.1038/sj.jhh.1002214] [PMID: 17460709]

[22] McInnis NH, Fodor G, Moy Lum-Kwong M, Leenen FH. Antihypertensive medication use and blood pressure control: A community-based cross-sectional survey (ON-BP). Am J Hypertens 2008; 21(11): 1210-5. [http://dx.doi.org/10.1038/ajh.2008.269] [PMID: 18772857]

[23] Hyman DJ, Pavlik VN. Characteristics of patients with uncontrolled hypertension in the United States. N Engl J Med 2001; 345(7): 479-86. [http://dx.doi.org/10.1056/NEJMoa010273] [PMID: 11519501]

[24] Ho PM, Magid DJ, Shetterly SM, et al. Importance of therapy intensification and medication nonadherence for blood pressure control in patients with coronary disease. Arch Intern Med 2008; 168(3): 271-6. [http://dx.doi.org/10.1001/archinternmed.2007.72] [PMID: 18268167]

[25] Kjeldsen SE, Jamerson KA, Bakris GL, et al. Predictors of blood pressure response to intensified and fixed combination treatment of hypertension: the ACCOMPLISH study. Blood Press 2008; 17(1): 7-17. [http://dx.doi.org/10.1080/08037050801972857] [PMID: 18568687]

[26] Mozheyko M, Eregin S, Vigdorchik A, Hughes D. A cross-sectional survey of hypertension diagnosis and treatment practices among physicians in Yaroslavl Region, Russia. Adv Ther 2012; 29(12): 1016-25. [http://dx.doi.org/10.1007/s12325-012-0064-2] [PMID: 23203238]

[27] Kobalova ZhD, Starostina EG, Kotovskaia IuV, et al. [Antihypertensive treatment compliance and obstacles to its improvement. Results of Russian program ARGUS-2]. Ter Arkh 2008; 80(3): 76-82. [PMID: 18441691]

[28] Roberts B, Stickley A, Balabanova D, McKee M. Irregular treatment of hypertension in the former Soviet Union. J Epidemiol Community Health 2012; 66(6): 482-8. [http://dx.doi.org/10.1136/jech.2010.111377] [PMID: 21051778]

[29] Greenberg HM, Galyavich AS, Ziganshina LE, Tinchurina MR, Chamidullin AG, Farmer RG. Identification and management of patients with hypertension in the polyclinic system of the Russian Federation. Am J Hypertens 2005; 18(7): 943-8. [http://dx.doi.org/10.1016/j.amjhyper.2005.01.012] [PMID: 16053991] 
[30] Loukianov MM, Boytsov SA, Yakushin SS, Martsevich SY, Vorobyev AN, Zagrebelnyy AV, et al. Concomitant cardiovascular diseases and antihypertensive treatment in outpatient practice (by the RECVASA registry data). Ration Pharmacother Cardiol 2016; 12 (1): 4-15. [http://dx.doi.org/10.20996/1819-6446-2016-12-1-4-15]

[31] Shalnova SA, Deev AD, Balanova YA. Treatment of hypertension in high-risk patients. Monotherapy or combination? Lechashij Vrach 2016; 7: 17-23.

[32] Hatori N, Sakai H, Sato K, et al. A survey of actual clinical practice concerning blood pressure control among patients with hypertension in Kanagawa 2014. J Nippon Med Sch 2016; 83(5): 188-95. [http://dx.doi.org/10.1272/jnms.83.188] [PMID: 27890892]

[33] Dinkler JM, Sugar CA, Escarce JJ, Ong MK, Mangione CM. Does age matter? Association between usual source of care and hypertension control in the US population: Data from NHANES 2007-2012. Am J Hypertens 2016; 29(8): 934-40. [http://dx.doi.org/10.1093/ajh/hpw010] [PMID: 26884134]

[34] Rose G. Seasonal variation in blood pressure in man. Nature 1961; 189: 235. [http://dx.doi.org/10.1038/189235a0] [PMID: 13743262]

[35] Andreeva G, Deev A, Isaikina O, Gorbunov V, Molchanova O, Lerman O, et al. Quality of life may influence the severity of seasonable variations of the ambulatory blood pressure level in patients with arterial hypertension. J Hypertens 2013; 39(e-Suppl A): 235-e129.

\section{2017 Posnenkova et al.}

This is an open access article distributed under the terms of the Creative Commons Attribution 4.0 International Public License (CC-BY 4.0), a copy of which is available at: https://creativecommons.org/licenses/by/4.0/legalcode. This license permits unrestricted use, distribution, and reproduction in any medium, provided the original author and source are credited. 